\title{
Integrated Approach to Workplace Diversity through Human Resource Management
}

\author{
*Sunday Samson Babalola, Lilita Marques \\ University of Namibia, Windhoek, Namibia \\ *sbabalola@unam.na
}

\begin{abstract}
Today's organisations are facing challenges of equity control, market size, and workplace diversity despite increase in profitability due to globalisation and technological advancements. This called for efficient utilization of human resource management (HRM) as its focus is on people management with the strategic proactive approach to workplace diversity. The paper calls for improve role of HRM and organisational management in creating conducive work environment, accurate and expansion of selection criteria for workplace diversity that include stable attributes such as emotional intelligence and dispositional factors such as task and people oriented and being culturally flexible. It conclude by advocating for HRM integrative approach to diversity as it synthesizes the literature and proposes key areas needed to management diversity.
\end{abstract}

Keywords: Workplace diversity, selection criteria, work climate, Human resource management

\section{Introduction}

Globalization has made organizations desiring success and relevance in economic development to require more interaction among people from diverse cultures, beliefs, and backgrounds, than ever before. Organizations need diversity as people no longer live and work in an insular marketplace to become more creative and innovative. The fences that hitherto hinder mobility of goods, services, and labour have been rendered extremely permeable through deregulation, technological advancement, and globalisation. The new economic reality has consequently led to the realization of employees' expertise as a vital and dynamic living treasure (Jacobs \& Jones, 1995), which is spread across different geographical regions of the world. It is only through the conscious adoption and implementation of policies for advancing employee expertise that organizations have continued to grow and be more productive. Torraco and Swanson (1995) noted that educational levels and the readiness to acquire higher levels of training in some part of the world are comparable to what is obtainable in the United States. This is why planning and location strategies of large corporations are increasingly targeted at countries other than the US.

Valuing diversity and having a diverse workforce are morally correct and make economic sense (Green, 2010), as it could be a key component of effective people management to improve workplace productivity. Gaining the arising benefits, organizations need to tap into increasingly globalized and diverse markets (Green, 2010). Diversity has been defined as acknowledging, understanding, accepting, valuing, and celebrating differences among people with respect to age, physical and mental ability, ethnicity, gender, and public assistance status (Esty, Griffin \& Schorr-Hirsh, 1995). This description covers "those individual differences that are socially and historically significant and which have resulted in differences in power and privilege" (Thomas, 2005, p. 9). Diversity is also the distribution of organizational members in terms of physical and psychological attributes. Physical attributes which promote workplace diversity are seen as easily detectable such as ethnicity, age, gender and skin colour (Berdahl \& Moore, 2006) and usually more enduring as it may form the first basis of alignment among diverse workers (Bezrukova, Thatcher \& Jehn, 2007). Psychological attributes include factors such as attitudes, preferences, belief system, life style, values, personality and expertise as it forms the basis for differences among the workforce. To McKay, Avery, Tonidandel, Morris, Hernandez and Hebl (2007), attributes such as attitudes, life style, values, are controllable more easily through training. While, certain attributes such as personality characteristics are relatively stable, it may require organization members to interact long enough before being influenced. Diversity has been expanded to mean the collective differences brought to the workplace, based on individual and group characteristics, attributes, values, beliefs, skills and abilities, backgrounds, socialization, life experiences, and power dynamics (Bagshaw, 2004; Esen, 2005; Konrad, 2006).

Researchers studying diversity have assessed the extent to which members of an organizational unit are similar or dissimilar to each other. For instance, studies on diversity, according to (Jackson, May \& 
Whitney, 1995) showed that numerous attributes which are of interest include age, gender, ethnicity and length of tenure in the organization, functional specialization, educational background, cultural values, and personality. The authors referred this as content of diversity. Content of diversity can either be a relational-oriented or task-oriented (Jackson, et al., 1995; Milliken \& Martins, 1996). Relational-oriented diversity refers to the distribution of attributes that are instrumental in shaping interpersonal relationships, but has no apparent direct implications for task performance. Task-oriented diversity refers to the distribution of performance relevant attributes. Notwithstanding, diversity has been suggested to promote greater understanding, communication and integration of different worldviews in decision-making and problem solving (McGuire \& Bagher, 2010). Consequently, diversity issues have permeated organizations, most especially, the multinational corporation, making it important for human resource management (HRM) managers to understand and address diversity. Unfortunately, the profession of human resource has not made enough or strong effort to create diversity as a mandatory topic in academic programs that train HRM professionals (Hite, McDonald, Bierema, Gedro, Kormanik \& Kravitz, 2009; Kuchinke, 2002) nor has it been included it as a key focus of its research agenda (Bierema, 2010). Although, workplace diversity requires the attention of management at all levels of the organization, still, it is an important element for HRM. This is because HRM's focus is on people management with the strategic proactive approach to workplace diversity in order to achieve organizational goals (McDonald, 1999). Kormanik and Rajan's (2010) study showed that diversity has largely been a HRM function, but it is limited to increasing the workforce representation of historically underrepresented groups (e.g., women, minorities) through recruitment and hiring practices. It is the view of this researcher that HRM has a significant role to play in fostering greater equality inclusion and fairness in the workplace with the objectives of helping diverse individuals and groups to regain important aspects of their identity and enjoy productive fulfilling careers.

Literature is clear on the fact that the survival, smooth functioning, and profitability of large organisations depend on the quality of its human capital and the level of person -job/organization fit (Arthur, Bell, Doverspike \& Villado, 2006; McCulloch \& Turban, 2007) which fall within the scope of HRM. . Most of the issues raised by these researchers might have been the result of development track pursued by the global corporations which Barnet and Muller (1974) described as contributing more to the exacerbation of world poverty, world unemployment and world inequality than to their solution. Experiences from Nigeria showed that the activities of multinational companies have resulted in continual environmental degradation, unemployment, widening gap between the poor and the rich and abject poverty mostly in the oil exploration region of Nigeria. These are in most cases responsible for youth restiveness and social disorder in the region. Omofonmwan and Odia (2009) study revealed that the causes of the crises in the Niger-Delta region could be linked to the inability of the multinational companies involved in the explorations of crude oil, and the government of Nigeria inability to alleviate the problem of diverse inequality in the region. For instance, capital-intensive technologies use generates high wage employment for few skilled workers with little employment for the most unskilled. It should be noted that oil well and gas contribute about 80 per cent of Federal government of Nigeria revenue.

Diversity management should thus be concerned with how effectively the workforce can be managed in achieving competitive advantage and business benefits, while being influenced to a large extent by organizational strategies and pressures from stakeholders (Florkowski, 1996). Researchers such as (Egan \& Bendick, 2003; Stuber, 2002) opined that adaptation of diversity management could be challenging in light of different legal and business environments as well as historical influences. The best approach to managing diversity should be geared towards its design and delivery so as to meet the expectations of stakeholders (Tayeb, 2003). Dietz and Petersen (2006) categorized managing diversity approaches into two, the macro and micro level approaches. The micro-level approach involves organizational issues, which Cox (2001) and Thomas and Ely (1996) hypothesized to moderate the relationship between workforce diversity and performance while, the micro level approach is on psychological models of discrimination and inter-group relations. This approach advocates for greater understanding and management of stereotypes, prejudices and discrimination (Dietz \& Petersen, 2006) as stereotypes and prejudices are considered immediate antecedents of discrimination. To Bassett-Jones (2005), managing diversity is the systematic planned commitment by organizations to recruit, retain, reward, and promote heterogeneous mix of employees. Against this background, this study discusses the role of HR managers in diversity management- visa-vice promotion of diversity-sensitive work climate, selection decision and training as preventative measures.

Management of Workforce Diversity: Managing workforce diversity is a topic of increasing concern in 
HRD (Chermack, Lynham \& Ruona, 2003; Ross-Gordon \& Brooks, 2004) as it centres on the premise that harnessing differences will create a productive workplace in which employees feel valued and their talents are used in the process of accomplishing organizational goals (Bagshaw, 2004). Valuing workforce diversity entails awareness of workplace behaviour, leveraging strengths, avoiding assumptions, acknowledging biases/prejudices and focusing on merit (Kormanik \& Rajan, 2010). Therefore, organizations should no longer limit workplace diversity to an affirmative action program, training intervention, or something 'nice to do' (SHRM, 2008). Although, Bassett-Jones (2005) revealed that the reason why workforce diversity is difficult to implement is due to what can be termed as 'preference for working in homogeneous groups (melting pot approach) and resistance to change.' Other reasons for difficulty in handling diversity may be due to a lack of consensus of what the term means, for instance, diversity has been approached in four different ways, namely, personality (skills and abilities), internal factors (gender, race, sexual orientation), external factors (culture, nationality, religion), and organizational factors (position, department, union/non-union) (Simmons-Welburn, 1999). This is perhaps why workplace diversity management is defined as a "comprehensive managerial process for developing an environment that works for all employees" (Thomas, 1992, p. 10). For successful management of diversity, HRM must be skilful in leadership, organizational development and change management, with excellent communication skills (Kreitz, 2008).

When an organisation is committed to workplace diversity, the HRM approach should be able to develop challenging, yet realistic goals for diversity interventions (Hubbard, 2004). In addition, HRM has to foster support for the creation and maintenance of internal labour market and skills that is based on an outcome-driven rather than process-driven approach (Bassett-Jones, 2005). Effective management of diversity requires attending and recognizing the diversity of all employees by "acknowledging individual employee needs and then accommodating these needs" (Wilson, 1997, p.18). HRM must consciously develop a culture of transformation in their organizations, so that diversity in the workplace can be embraced as a tool that can promote organizational strategy and competitiveness (Robinson \& Harvey, 2008). As Denton and Vloeberghs (2003) noted, this type of action could help reduce employees' fear of being replaced and the uncertainty of future career, thus, allowing for individual commitment to organizational transformation. This process will help address the fear often expressed by disadvantaged employees' lack of progress in transformation. HRM must therefore create a dynamic work environment that actively encourages coaching and mentoring, appreciates the advantages of workplace diversity, and that ensures employees' belief in organizational change (Kerr-Phillips \& Thomas, 2009). This is of particular importance given the underlying culture of mistrust (Thomas \& Jain, 2004) due to the challenges of historical past, exclusionary workplace practices and the current compliance with affirmative action (Denton \& Vloeberghs, 2003).

\section{Assumptions of Workforce Diversity and HRM}

Workforce diversity: Two fundamental explanations for explaining diversity are based on a sociological and psychological framework. Sociological explanations assume that social groups compete with each other for material and social resources, creating a situation of conflict rather than cooperation (Blalock, 1967). Within this perspective, social groups are defined by demographic categories (e.g. based on race, gender, age). These readily detectable attributes signals provide information on group membership and also determine whether interactions will be characterized by competition or cooperation. Most psychological explanations emphasize the role of personality, cognition, and values as determinants of behaviour. That is why those that focus on the role of individual differences often assume that the more relevant underlying attributes should be factors like beliefs and values. However, social identity theory is positioned between these two extremes as it assumes that social and psychological processes mutually influence each other. Social identity theory predicts that people will exhibit favourable bias toward others who are viewed as members of their in-group while viewing themselves as being in conflict with out-group members (Turner \& Haslam, 2001). Researchers (Gibson \& Vermeulen, 2003; Hogg \& Terry, 2000) using social identity theory suggested that individuals, including workers, sort and categorize themselves into homogenous subgroups base on salient similar attributes (of gender, ethnicity, expertise, values). They then act in agreement with such salient identities, which favour situations that maintain and enhance positive evaluation of their own groups over other groups. This type of positive evaluations promotes both the individual and group self-esteem. It is through group membership that individuals develop social identity, which serves as social-cognitive schema (norms, values, and beliefs) for grouprelated behaviour (Korte, 2007). This is perhaps why Prasad, Pringle, and Konrad (2006) stated that group identification might sometimes lead to in-group bias and out-group discrimination. It is therefore 
necessary for the organization and its representative such as HRM to moderate these consequences.

Human Resource management models: In their study, Kossek and Lobel (1996) stated that traditional HRM models foster workforce homogenization and similarity, which tend to hinder the organization's ability to respond to important environmental changes. Similarly, Paauwe and Richardson (1997) posited that HRM activities give rise to HRM outcomes, which subsequently influence the performance of the firm, through contingency and control variables, such as age, size, sector and technology. In view of this, strategic decisions on diversity management should be built in the design and policies of HRM before implementation of such policies. Grove, French, and Maconachie's (2003) study identified two strategies in approaching diversity management. These strategies revolve around the employment relationship, which are either 'soft' resource based, or 'hard' resource based. The soft style involves the integration of individuality, values such as trust and commitment to the business strategy of the organisation; while the hard style emphasize cost minimisation, the leanness in production and resource-based view of labour. The 'soft' resource based strategy, which is more attuned to diversity is what Legge (1995) called 'developmental humanism.' The hard style is often referred to as the 'utilitarian instrumentalism'. The Choice model of Analoui (2007) which has been viewed as an holistic effective approach towards HRM performance, laid the drivers for formulating HRM policies and frameworks on three sources namely; the organisation, personal and external. To Dessler (2003), these sources constitute the input to HRM policy formulation; which are transported to functional level that can be influenced directly or/and indirectly during the implementation; and thus end at an output level that affects the individual, organisation and society through improved performance and effectiveness to work and life. However, according to Senge (1990) whatever model that is used, the HRM professionals are expected to be technical, cognitive, flexible and communicative so as to achieve a learning organisation, which is efficient and innovative.

HRM, according to Sippola (2007) can only support diversity by being able to attract, motivate, develop and retain employees and adapt to environmental changes and technology shifts when its policy is able to pay attention to the different subgroups' needs. It is therefore important that organizations adapt and set up a new culture and ways of working (Storey, 2001), as well as pay attention to careful diversity management as a long-term investment so as to gain competitive advantage (Caproni, 2005). Indeed, Wentling and Palmaand Rivas (1998) affirmed that redrafting and revision of HRM policies and procedures (e.g. recruiting, pay equity, flexible work, career development, mentoring) which permit fairness and equity, have been found to be critical in supporting diverse needs and also considered as the second best strategy for managing diversity after training and education. This is especially so, according to Gagnon and Cornelius (2002), when systemic changes within HRM are seen as crucial for successful systemic and structural integration of diversity.

\section{Application of and Workplace Diversity Management}

Changes within organizations arising from factors such as downsizing, outsourcing and the impact of globalization and technology are presumed to affect HRM (Green, Lopez, Wysocki \& Kepner, 2002). Conditions as this, may pose serious challenges to the HRM workplace diversity initiatives and diversity programs (Porter, 1995). Managing diversity is not an isolated problem to be solved, but a continuous exercise within the life span of the organisation. It is this commitment and shared understanding that are needed to sustain the willingness to work together when employees do not share skills and abilities, values, experiences, culture, and ways of interpreting meaning and solving problems (Zane, 2002).

Value proposition for a diverse work climate: The need for efficient management of workplace diversity depends on the creation of an organizational work climate, which will unify employees under common value sets. Cox (1991) conceptualized an authentic diverse work climate in terms of a multicultural organisation whereby diversity is highly valued and members of all demographic groups are given the opportunity to develop their capacities. Furthermore, members of different socio-cultural backgrounds are represented across the hierarchy of the organisation (Wolfson, Kraiger \& Finkelstein, 2011). More importantly though, is that multicultural organisations develop common values that shape the work environment (Cox, 2001). Values are defined as the shared ideas, thoughts, and basic principles, which are internalized by members of a group or organisation (Czinkota, Ronkainen \& Moffett, 2009). These shared values then become the benchmark with which members of the organisation evaluate and judge various situations, actions, applications, and people (Polat, 2012). Common values reflect the basic aims, ideals and standards of an organisation. Moreover, the creation of common organisational values compels 
members of an organisation to focus on a common goal rather than fixating on individual differences. Not that individual difference are regarded as unimportant, rather, organisations should emphasize valuing diversity as a top priority value. The impetus lies on HRM to develop a strong value statement reflecting the organisation's commitment towards valuing diversity and creating a work climate that affords every individual the opportunity to reach his or her full potential. Examples of specific values that may reflect valuing diversity include democracy, fairness, mutual respect, integrity, equality and team spirit (Polat, 2012). Wolfson, et al. (2011) maintained that employee perceptions of how effective an organisation manages a diverse work environment has a significant impact on various job attitudes such as organisational commitment, job satisfaction, loyalty, and interpersonal relations with co-workers and supervisors. The challenge, however is for members of organisations to value diversity beyond "the right thing to do" and see the tangible outcomes of valuing diversity. HRM therefore has to explore human capital metrics and measure the return on investment of effective diversity management (Hubbard, 2004). In this way diversity management is cemented as a strategic initiative, rather than a mere exercise (Craig, 2010).

In their work, McKay et al. (2007) stated that minority groups in diverse workplace strongly rely on the organization to formulate and implement policies that provide and enhance a peaceful work climate as well as minimize the adverse effects of discrimination. Favourable work environment should have such action policies of equal access to training and promotion opportunities; policies on workplace diversity and open communication where every worker are exposed to policies on diversity. The assumption is that when employees work in a positive diversity-sensitive climate, their levels of efficiency and effectiveness are often translated into better adjustment and high level of organizational performance and profitability. Similarly, organisational goals on workplace diversity need to be explicit, as RossGordon and Brooks (2004) asserted. These goals are the fundamental influence on diversity efforts of HRM. By emphasising super-ordinate goals and identifying the distinctions among workplace members could lead to blurriness of views thus negating the true value of diversity (Swann, Polzer, Seyle \& Ko, 2004). However, collectivistic value sets may result in diversity-blind attitude and an emphasis on sameness (Byrd, 2009). Fostering inclusivity and respect for the dignity of the individual could help an organisation to free itself from the costly lawsuits, hostile environments and divisive conflict-ridden cultures (Aghazadeh, 2004). HRM must recognize their own cultural biases and prejudices, in addition to understand discrimination and its consequences. Such knowledge will help HRM to implement strategy in a way to create 'sufficient flexibility' (Tayeb, 2003, p. 252) in meeting employees' diverse needs. As Schneider and Barsoux (2003) posited, adaptation of HRM policies, practices and organizational culture to local environments is crucial in managing local diversity if one is to be fair and relatively free from biases.

Selection criteria: Management through its HR managers must make selection decisions based on appropriate selection criteria that meet the challenges of diverse workplace. This is because as the economy moves labour across national boundaries, effective interaction among diverse workers becomes more critical (Roberson \& Stevens, 2006). The selection criteria for jobs should be diversity-sensitive so as to prepare and select candidates with required attributes. Traditional selection criteria for jobs usually emphasize technical competence and the willingness of the worker to work in a diverse workplace (Mendenhall, Kuhlman, Stahl \& Osland, 2002). Emerging evidence has shown that this type of criteria no longer guarantees worker's adjustment and performance in a diverse workplace (Shaffer, Harrison, Gregersen, Black \& Ferzandi, 2006). Although talent and skill should be the primary factors in acquiring a job, diverse employees may lead to greater efficiency and effectiveness in an organization, according to (Rosenbloom \& Kravchuk, 2005). It has been suggested that selection criteria need to be broadened to include stable attributes and competencies. The stable attributes are relatively enduring patterns of feeling, thinking, and behaving in response to people, events, and issues. A study (Shaffer et al., 2006) on stable attributes indicated that workers that were emotionally stable, outgoing, agreeable, and innovative were effective in work and non-work settings. To these scholars, such attributes will assist in facilitating "the understanding and implementation of new behaviours needed in a foreign cultural environment" (Shaffer et al., 2006, p. 113). A selection criterion, as a diversity management technique, is a preventative measure to workplace diversity. This is because the selection decision will favour only the candidates that can function very well in a diverse work environment. Post-selection period must include positive work behaviour relationship that favours workplace diversity. HR policies and practices related to recruitment and career progression must be able to ensure that the demographic make-up of the entire organization is conducive to the functioning of a diverse workforce. As such, practices that create diversity at entry levels but do not support the presence of diversity at higher levels in the organization may be particularly 
harmful in that they help to set the stage for dysfunctional team processes.

Human Resource Development: Human resource development as part of the domain HRM has gained significant attention in promoting diversity management issues (Jayne \& Dipboye, 2004). According to Ford and Fisher (1996), human resource development can act as an effective tool in culture change, when used in more holistic, proactive and innovative ways, to align the goals of organization and the needs of individuals, as well as to increase the effectiveness of diversity initiatives. Training has however been identified as the best practice in managing diversity (Lockwood, 2006); a common practice in organizations (Fegley, 2006); and an issue in the delivery of management leadership training (Kormanik \& Rajan, 2010). Diversity training thus has advanced from compliance-oriented content to strengthening employee-working relationships by focusing on the integration of all aspects of diversity to improve organizational effectiveness (Anand \& Winters, 2008; Paluck, 2006). HR working with MNC in volatile nations (such as Nigeria, Kenya, Angola, DRC, Colombia and Mexico) where there are security and terrorism concerns should be able to provide awareness training for employees; most especially where kidnapping of foreigners is commonplace (Grobovsky, 1999). Although, the management of the HR function in MNCs could be complicated by the need to adapt HR policies and procedures to the differences among countries in which each subsidiary is based.

Diversity training is the process by which a workforce is educated about the cultural, socio-economic, racial and religious differences among employees and how to embrace the differences so as to create and maintain an effective work environment (Lai \& Kleiner, 2001). To Pendry, Driscoll and Field, (2007), the primary goal of diversity training is to facilitate the integration of minorities into the workplace by attempting to inculcate the skills, knowledge and motivation to work productively. In addition, diversity training aims to facilitate interacting effectively with a diverse customer population in the workforce. Diversity training serves as a guide in incorporating new worldviews, problem solving and decisionmaking activities (McGuire \& Bagher, 2010) and can be divided into two categories, namely awarenessbased and skilled-based. Awareness-based training emphases employee knowledge and sensitivity to diversity issues, while, skill-based training centres on behaviour change (Day \& Glick, 2000). Business diversity training often concentrates on awareness of individual differences, working effectively with others, and balancing special needs of workers. Addressing sensitive issues that relate to identities and cognitive worldviews may however weigh down diversity awareness training. An increase in workforce mobility and the desire for effectiveness have made workplace diversity more challenging, thus making the need for adequate diversity training a high priority for HR managers. This is because; diversity training ought to produce increase in collaboration and interaction with people from different backgrounds and also the ability to understand and make better decisions. Diversity training is thus an important variable in promoting better interaction skills in individuals with the aim of alleviating the arising cultural and work attitudinal differences that shape interaction outcomes. Moore (1999) advocated for the adoption of a holistic approach to diversity training and used the term "diversity integration" to emphasize the role of managers in integrating diversity.

The reason why diversity training fails to accomplish the organisational goals of training is due to a lack of integrating diversity into management systems, policies, and practices (Ferdman \& Brody, 1996). If HR development is to make a legitimate claim to its roles as employees' advocate and organization developer, the HR managers must be able to guide organization through the following:

- The need to ensure that diversity training is aligned with organizational goals, and their supporting policies. That is, it must be able to optimally frame or reframe the diversity training (Holladay, Knight, and Paige \& Quinones, 2003) to address any associated negative perceptions and also making use of stakeholders' value and their language.

- Focusing on cultural change and learning in the entire organization, rather than promoting fairness and avoiding discrimination. This is relevant in cases such as the type in Niger Delta area of Nigeria. As McKay et al. (2007) suggested psychological attributes of attitudes; life style and values can be adapted more easily through diversity training to reflect the benefits and peculiarities of the workplace.

- HR managers must be able to take deliberate and practical steps to manage and integrate diversity education for positive outcomes through the provision of social networks, mentoring for everyone concerned in the organization and the development of interpersonal skills.

- HRM professional body should be able to liaise with various training institutions or programmes that are involved in teaching, research, and practice on diversity issues. This may involve a thorough 
review of diversity education that will help in equipping graduates of HRM programmes to lead a diverse workforce.

\section{Discussion and Conclusion}

This paper extends past research and likewise emphasizes the positive influence of HRM on workplace diversity. Changes in the demographics and composition of workforces are inevitable, which brings along critical challenges for HRM. Organizations vary in their motivation and effort to value diversity. Some organizations truly value diversity, which is also then reflected in their work practices. Other organizations implement diversity initiatives simply to comply with legislation. This approach merely attempts to stop discrimination in the workplace and does not necessarily oblige employers to actively promote diversity. Organizations have to take a stronger stance regarding valuing diversity, which should be reflected in the organizations' culture, design, and policies. Furthermore, in promoting diversity, organizations have to look beyond traditional criteria for recruitment and selection to include diversitysensitive criteria. In addition, organizations have to be committed to the on-going development of its human resources through capacity building, succession planning, and career development (Mello, 2011). Organizations are increasingly under pressure to compete in a global market with diverse customers (DeSimone \& Werner, 2012). This requires attracting and retaining employees with the right competencies and attributes, and continuously investing in their development. In so doing, organizations will enjoy the benefits of diverse contributions, create a positive work environment for everyone, and ensure the full utilisation of the total workforce.

It can be concluded that workforce diversity is an important topic, which should be of increasing concern for HR managers, as its central objective cannot be separated from business strategy. Moreover, it is important to view diversity from an investment perspective as it allows an organization to determine how to best invest in its people. It is an issue that is germane to HRM's performance efficiency. Thus, it is suggested that HR managers must be able to guide organizations through and provide leadership in managing diversity in a way that fully realize the potential benefits that differences can bring. That is, be aware of behaviour and attitudes, acknowledge biases/prejudices, avoid assumptions, and focus on job performance and conduct. This in turn will help the HR manager in his/her substantive activity such as a leadership development and explicit focus on workforce diversity. HRM may be able to achieve these goals through an integrated approach with the combined broader role of organizational management.

\section{References}

Aghazadeh, S. Y. (2004). Managing diversity as an essential resource for improving organisational performance. International Journal of Productivity and Performance Management, 52(6), 521-531.

Analoui, F. (2007). Strategic human resource management, UK: Thomson Learning

Anand, R. \& Winters, M. F. (2008). A retrospective view of corporate diversity training from 1964 to present. Academy of Management Learning and Education, 7(3), 356-372.

Arthur, W. Jr., Bell, S. T., Doverspike, D. \& Villado, A. J. (2006). The use of person-organization fit in employment decision-making: An assessment of its criterion-related validity. Journal of Applied Psychology, 91(4), 786 - 801.

Bagshaw, M. (2004). Is diversity divisive? A positive training approach. Industrial and Commercial Training, 36, 153-157.

Barnet, J. R. \& Muller, R. E. (1974). Global reach: The power of the multinational corporations, (pp. 150163). London: Jonathan Cape Ltd.

Bassett-Jones, N. (2005). The paradox of diversity management, creativity and innovation. Creativity and Innovation Management, 14(2), 169-175.

Berdahl, J. L. \& Moore, C. (2006). Workplace harassment: Double jeopardy for minority women. Journal of Applied Psychology, 91, 426-436.

Bezrukova, K., Thatcher, S. M. B. \& Jehn, K. (2007). Group heterogeneity and faultiness: Comparing alignment and dispersion theories of group composition. In K. J. Behfar, \& L. L. Thompson (eds.), Conflict in organizational groups: New directions in theory and practice, (pp. 57-92). Evanston, IL: The Northwestern University Press.

Bierema, L. L. (2010). Resisting HRD's resistance to diversity. Journal of European Industrial Training, $34(6), 565-576$.

Blalock, H. M. (1967). Toward a theory of minority group relations. New York: Wiley. 
Byrd, M. Y. (2009). Diversity training: what are we really talking about? Paper presented at the Academy of Human Resource Development Conference, Washington, DC.

Caproni, P. J. (2005). Management skills for everyday life, 2nd ed. New Jersey: Prentice Hall.

Chermack, T. J., Lynham, S. A. \& Ruona, W. E. A. (2003). Critical uncertainties confronting human resource development. Advances in Developing Human Resources, 5, 257-271.

Cox, T. (1991). The multicultural organisation. Academy of Management Executive, 5, 34-47.

Cox, T. (2001). Creating the multicultural organization: A strategy for capturing the power of diversity. San Francisco, UAS: Jossey-Bass

Craig, C. B. (2010). A new way to build the business case for diversity based on the numbers: the diversity profit equation. The Diversity Factor, 18(2), 1-10.

Czinkota, M. R., Ronkainen, I. A., \& Moffet, M. H. (2009). International business. Wiley: European Business Edition.

Day, N. E. \& Glick, B. J. (2000). Teaching diversity: A study of organizational needs and diversity curriculum in higher education. Journal of Management Education, 24, 338-352.

Denton, M. \& Vloeberghs, D. (2003). Leadership challenges for organizations in the new South Africa. Leadership and Organization Development Journal, 24(2), 84-95.

DeSimone, R. L. \& Werner, J. M. (2012). Human resource development (6 $6^{\text {th }}$ ed). Canada: Cengage Learning.

Dessler, G. (2003). Human resource management, (9th ed.). Prentice Hall

Dietz, J. \& Peterson, L-E. (2006). Diversity management. In G. K. Stahl \& I. Björkman (eds.), Handbook of research in international human resource management, (pp. 223-244). UK: Edward Elgar Publishing Limited.

Eden, L. \& Miller, S. R. (2004). Distance matters: Liability of foreignness, institutional distance, and ownership strategy. Bush School working paper number 404, Texas A \& M University, College Station.

Egan, M. L. \& Bendick, M. (2003). Workforce diversity initiatives of U.S. multinational corporations in Europe. Thunderbird International Business Review, 45(6) 701-727.

Esen, E. (2005). 2005 Workplace diversity practices: Survey report. Alexandria, VA: Society for Human Resource Management.

Esty, K., Griffin, R. \& Schorr-Hirsh, M. (1995). Workplace diversity. A managers guide to solving problems and turning diversity into a competitive advantage. Avon, MA: Adams Media Corporation.

Fegley, S. (2006). 2006 Workplace diversity and changes to the EEO-1 process: Survey report. Alexandria, VA: Society for Human Resource Management.

Ferdman, B. \& Brody, S. E. (1996). Models of diversity training. In D. Landis, \& R. S. Bhagat (eds.), Handbook of intercultural training, $2^{\text {nd }}$ ed., (pp. 282-303). Thousand Oaks, CA: Sage.

Florkowski, G. W. (1996). Managing diversity within multinational firms for competitive advantage. In E. E. Kossek, \& S. A. Lobel (eds.), Managing diversity: Human resource strategies for transforming the workplace, (pp. 337-364). Massachusetts: Blackwell Publishers.

Ford, K. \& Fisher, S. (1996). The role of training in a changing workplace and workforce: New perspectives and approaches. In E. E. Kossek, \& S. A. Lobel (eds.), Managing diversity: Human resource strategies for transforming the workplace, (pp. 164-193). Massachusetts: Blackwell Publishers.

Gagnon, S. \& Cornelius, N. (2002). From equal opportunities to managing diversity to capabilities: A new theory of workplace equality? In N. Cornelius (ed.), Building workplace equality: Ethics, diversity and inclusion, (pp.13-58). Cornwall: Thomson.

Gaur, A. S. \& Lu, J. W. (2007). Ownership strategies and survival of foreign subsidiaries: Impacts of institutional distance and experience. Journal of Management, 33(1), 84-110.

Gedajlovic, E. \& Shapiro, D. M. (2002). Ownership structure and firm profitability in Japan. Academy of Management Journal, 45, 565-575.

Gibson, C. B. \& Vermeulen, F. (2003). A healthy divide: Subgroups as stimulus for team learning behaviour. Administrative Science Quarterly, 48, 202-239.

Green, K. A., Kepner, K., López, M. \& Wysocki, A. (2002). Diversity in the workplace: Benefits, challenges, and the required managerial tools. University of Florida IFAS Extension, Retrieved September 28, 2012. http://edis.ifas.ufl.edu/HR022.

Green, T. K. (2010). Race and sex in organizing work: "Diversity", discrimination and integration. Emory Law Journal, 59, 585-647.

Grobovsky, L. (1999). Protecting your workers abroad with a global diversity strategy. Canadian HR Reporter, November 1, 15-16. 
Grove, R., French, E. \& Maconachie, G. (2003). Managing diversity HR strategy and competitive advantage: A resource based approach. Proceedings of International HRM Conference June, University of Limerick, Ireland.

Hite, L., McDonald, L., Bierema, L. L., Gedro, J., Kormanik, M. \& Kravitz, D. (2009). The importance of diversity in the HRD curriculum. Proceedings of the Academy of Human Resource Development Conference, Washington, D.C.: Academy of Human Resource Development.

Hogg, M. A. \& Terry, D. J. (2000). Social identity and self-categorization processes in organizational contexts. Academy of Management Review, 25, 121-140.

Holladay, C. L., Knight, J. L., Paige, D. L. \& Quinones, M. A. (2003). The influence of framing on attitudes toward diversity training. Human Resource Development Quarterly, 14(3), 245-263.

Hubbard, E. E. (2004). The diversity scorecard: Evaluating the impact of diversity on organizational performance. Burlington, MA: Elsevier Butterworth-Heinemann.

Jackson, S. E., May, K. E. \& Whitney, K. (1995). Understanding the dynamics of diversity in decisionmaking teams. In R. A. Guzzo \& E. Salas (eds.), Team effectiveness and decision making in organizations, (pp. 204-261). San Francisco: Jossey-Bass.

Jacobs, R. L. \& Jones, M. J. (1995). Structured on-the-job training: Unleashing employee expertise in the workplace. San Francisco: Berrett-Koehler.

Jayne, M. E. A. \& Dipboye, R. L. (2004). Leveraging diversity to improve business performance: Research findings and recommendations for organizations. Human Resource Management, 43(4), 409-424.

Kerr-Phillips, B. \& Thomas, A. (2009). Macro and micro challenges for talent retention in South Africa. $S A$ Journal of Human Resource Management, 7(1), 82-91.

Konrad, A. M. (2006). Leveraging workplace diversity in organizations. Organization Management Journal, $3,164-189$.

Kormanik, M. B. \& Rajan, H. C. (2010). Implications for diversity in the HRD curriculum drawn from current organizational practices on addressing workforce diversity in management training. Advances in Developing Human Resources, 12(3), 367-384.

Korte, R. F. (2007). A review of social identity theory with implications for training and development. Journal of European Industrial Training, 31(3), 166-180

Kossek, E. E. \& Lobel, S. A. (1996). Managing diversity: Human resource strategies for transforming the workplace. Cambridge, MA: Blackwell.

Kreitz, P. A. (2008). Best practices for managing organizational diversity. The Journal of Academic Librarianship, 34(2), 101-120.

Kuchinke, K. P. (2002). Institutional and curricular characteristics of leading graduate HRD programs in United States. Human Resource Development Quarterly, 13(2), 127-143.

Lai, Y. \& Kleiner, B. H. (2001). How to conduct diversity training effectively. Equal Opportunities International, 20(5/6/7) 14-8.

Legge, K. (1995). HRM: Rhetorics and realities. Basingstoke: Macmillan Business.

Lockwood, N. R. (2006). Workplace diversity series Part III: The impact of diversity initiatives. Alexandria, VA: Society for Human Resource Management.

McCulloch, M. C. \& Turban, D. B. (2007). Using person-organization fit to select employees for highturnover jobs. International Journal of Selection and Assessment, 15(1), 63-71.

McDonald, D. (1999). Human resource management (HRM) strategy in Japanese companies: Formulating a conceptual framework of HRM Strategy from practice. Keiken Ronshu (Graduate School of Economics, Daito Bunka University) 15, 147-163.

McGuire, D. \& Bagher, M. (2010). Diversity training in organizations: An introduction. Journal of European Industrial Training, 34(6), 493-505.

McKay, P. F., Avery, D. R., Tonidandel, S., Morris, M. A., Hernandez, M. \& Hebl, M. R. (2007). Racial differences in employee retention: Are diversity climate perceptions the key? Personnel Psychology, 60(1) 35-62.

Mello, J. A. (2011). Strategic management of Human Resources (3rd ed). Canada: Cengage Learning.

Mendenhall, M. E., Kuhlman, T. M., Stahl, G. K. \& Osland, J. S. (2002). Employee development and expatriate assignments. In M. Gannon, \& F. Newman (eds.), Handbook of cross-cultural management, (pp.155-183). Oxford, England: Blackwell Publishers.

Milliken, F. J. \& Martins, L. L. (1996). Searching for common threads: Understanding the multiple effects of diversity in organizational groups. Academy of Management Review, 21, 402-433.

Moore, S. (1999). Understanding and managing diversity among groups at work: Key issues for organizational training and development. Journal of European Industrial Training 23, 208-217. 
Neubaum, D. O. \& Zahra, S. A. (2006). Institutional ownership and corporate social performance: The moderating effects of investment horizon, activism, and coordination. Journal of Management, 32(1) 108-131.

Omofonmwan, S. I. \& Odia, L. O. (2009). Oil exploitation and conflict in the Niger-Delta Region of Nigeria. Journal of Human Ecology, 26(1), 25-30

Paauwe, J. \& Richardson, J. (1997) Strategic human resource management and performance: An introduction. International Journal of Human Resource Management, 8(3), 257-262.

Paluck, E. L. (2006). Diversity training and intergroup contact: A call to action research. Journal of Social Issues, 62(3), 577-595.

Pendry, L. F., Driscoll, D. M. \& Field, S. C. T. (2007). Diversity training: Putting theory into practice. Journal of Occupational \& Organisational Psychology, 80, 27-50.

Polat, S. (2012). Organizational values needed for diversity management. Educational Sciences: Theory \& Practice, 12(2), 1409-1418.

Porter, J. C. (1995). Facilitating cultural diversity. Journal of Management in Engineering, 11, 39-43.

Prasad, P., Pringle, J. K. \& Konrad, A. M. (2006). Examining the contours of workplace diversity: Concepts, contexts and challenges. In A. M. Konrad, P. Prasad, \& J. K. Pringle (eds.), Handbook of workplace diversity, (pp. 1-22). Sage Publications.

Probst, T. M. \& Lawler, J. (2006). Cultural values as moderators of employee reactions to job insecurity: The role of individualism and collectivism. Applied Psychology: An International Review, 55(2), $234-254$.

Roberson, Q. M. \& Stevens, C. K. (2006). Making sense of diversity in the workplace: Organizational justice and language abstraction in employees' accounts of diversity-related incidents. Journal of Applied Psychology, 91(2) 379-391.

Robinson, D. A., \& Harvey, M. (2008). Global leadership in a culturally diverse world. Management Decision, 46(3), 466-480.

Rosenbloom, D. H. \& Kravchuk, R. S. (2005). Public administration: Understanding management, politics, and law in the public sector ( $6^{\text {th }}$ ed.). Boston: McGraw-Hill.

Ross-Gordon, J. M., \& Brooks, A. K. (2004). Diversity in human resource development and continuing professional education: What does it mean for the workforce, clients, and professionals? Advances in Developing Human Resources, 6, 69-85.

Rothaermel, F. T., Kotha, S. \& Steensma, H. K. (2006). International market entry by US Internet firms: An empirical analysis of country risk, national culture, and market size. Journal of Management, 27(11), 1033-1056.

Schneider, S. C. \& Barsoux, J. (2003). Managing across cultures. Harlow, UK: Financial Times and Prentice Hall.

Senge, P. (1990). The fifth discipline: The art and practice of learning organisation. New York: Doubleday Currency

Shaffer, M. A., Harrison, D. A., Gregersen, H, Black, J. S. \& Ferzandi, L. A., (2006). You can take it with you: Individual differences and expatriate effectiveness. Journal of Applied Psychology, 91(1), 109-125.

Simmons-Welburn J. (1999). Diversity dialogue groups: A model for enhancing work place diversity. Journal of Library Administration, 27, 111-121.

Sippola, A. E. I. (2007). Essays on human resource management perspectives on diversity management. Acta Wasaensia, 180, 234.

Society for Human Resource Management (2008). 2007 State of workplace diversity management. Alexandria, VA: Author.

Storey, J. (2001). Human resource management: A critical text, 2nd ed. London: Thomson Learning.

Stuber, M. (2002). Corporate best practice: What some European organizations are doing well to manage culture and diversity. In G. F. Simons (ed.), Euro Diversity: A business guide to managing difference. Woburn, MA: Butterworth-Heinemann.

Swann, W. B., Polzer, J. T., Seyle, D. C. \& Ko, S. J. (2004). Finding value in diversity: Verification of personal and social self-views in diverse groups. Academy of Management Review, 29(1), 9-27.

Tayeb, M. H. (2003). Institutional differences across the world. In M. H. Tayeb (ed.), International management: Theories and practices. Harlow, UK: Pearson Education.

Thomas, A. \& Jain, H. C. (2004). Employment equity in Canada and South Africa: Progress and propositions. International Journal of Human Resource Management, 15(1), 36-55.

Thomas, D. A. \& Ely, R. J. (1996). Making differences matter: A new paradigm for managing diversity. Harvard Business Review, 74(5), 79-90.

Thomas, K. M. (2005). Diversity dynamics in the workplace, College ed. Belmont, CA: Wadsworth.

Thomas, R. R., Jr. (1992). Beyond race and gender: Unleashing the power of your total work force by 
managing diversity. New York: AMACOM.

Torraco, R. J. \& Swanson, R. A. (1995). The strategic roles of human resource development. Human Resource Planning, 18(4), 10-21.

Turner, J. C. \& Haslam, S. A. (2001). Social identity, organizations and leadership. In M. Turner (ed.), Groups at work: Theory and research (pp. 25-65). London: Lawrence Erlbaum.

Wentling, R. M. \& Palma-Rivas, N. (1998). Current status and future trends of diversity initiatives in the workplace: Diversity experts' perspective. Human Resource Development Quarterly, 9(3), 235253.

Wilson, T. (1997). Diversity at work: The business case for equity. Toronto, Ontario, Canada: Wiley.

Wolfson, N., Kraiger, K. \& Finkelstein, L. (2011). The relationship between diversity climate perceptions and workplace attitudes. The Psychologist-Manager Journal, 14, 161-176.

Zane, N. C. (2002). The glass ceiling is the floor my boss walks on: Leadership challenges in managing diversity. Journal of Applied Behavioural Science, 38, 334-354. 